\title{
UMA REFLEXÃO SOBRE A PRECARIZAÇÃO DO TRABALHO DOCENTE
}

Cláudio Braz de Figueiredo, Erika Porceli Alaniz , Pedro Luis Bilheiro .

Universidade do Oeste Paulista - UNOESTE, Mestrado em Educação, Presidente Prudente, SP. E-mail: claudiogerente16@hotmail.com, porcelierika@yahoo.com.br, bilheiro@unoeste.br.

\section{RESUMO}

Este traz uma reflexão sobre a flexibilização e precarização do trabalho docente. Para esta reflexão, utilizou-se a pesquisa bibliográfica. Os resultados apontaram que o trabalho docente vem passando por mudanças estruturais que vieram a impor a estes profissionais novas formas de lidar com o cotidiano escolar e resistência às condições de trabalho vivenciada pelos docentes, pois as condições impostas têm ocasionado mudanças pretensiosamente negativas na categoria.

Palavras-chave: Flexibilização, Precarização, Trabalho docente.

\section{A REFLECTION ON THE PRECARIOUS WORK TEACHER}

\section{ABSTRACT}

This brings a reflection about flexibility and precarious work. For this reflection, the bibliographical research. The results showed that the teaching work comes passing by structural changes that came to enforce these professionals new ways to cope with daily life and resistance to working conditions experienced by teachers, because the conditions have caused changes in the negative category pretentiously. 


\section{INTRODUÇÃO}

O presente artigo foi motivado pela discussão sobre a precarização do trabalho docente realizada na disciplina "Estado e Políticas Públicas em Educação" do Programa de Mestrado em Educação da Universidade do Oeste Paulista, no segundo semestre de 2015, ministrada pela Profa. Dra. Erika Porceli Alaniz.

Com os desafios enfrentados pela educação em nosso país, a temática sobre a precarização do trabalho docente tem se tornado mais presente e enseja a necessidade de reflexões teóricas que leve a compreensão de como os professores são afetados pelas condições de trabalho vivenciadas.

Oliveira (2008) discute o trabalho docente e sua precarização comparando-o ao processo de trabalho ocorrido na fábrica. A autora utiliza-se dos conceitos de trabalho produtivo/improdutivo, desenvolvidos por Karl Marx, para afirmar que há um processo de proletarização da categoria docente em curso.

Assim, este estudo teve como objetivo trazer uma reflexão a cerca da temática a precarização do trabalho docente na atualidade, mostrando sua relação com o mundo do trabalho e como os professores são afetados nesse processo.

\section{METODOLOGIA}

Utilizou-se de pesquisa bibliográfica realizada com base em artigos, capítulos de livros e livros que retratam a temática. Para a concretização do objetivo, fez-se, inicialmente, o levantamento na base de dados do Scielo (Scientific Eletronic Library Online). A escolha por essa base de dados justifica-se pela qualidade do material vinculado a ela, por apresentar diversas revistas indexadas e por estar disponível aos usuários, de forma online, o que possibilita o acesso a textos completos.

Como critério de seleção dos trabalhos encontrados na área, optou-se por focar o levantamento de publicações científicas, produzidas nos últimos 16 anos, entre 2000 a 2015 . A partir desse recorte, os descritores utilizados na base de dados Scielo foram: "precarização do trabalho docente", "profissionais da educação e precarização trabalho docente". Sendo assim, os resultados encontram-se no Quadro 1, logo abaixo.

Quadro 01. Busca de artigos científicos na base Scielo.

\begin{tabular}{|l|c|c|}
\hline \multicolumn{1}{|c|}{ Descritor } & $\begin{array}{c}\text { Artigos } \\
\text { disponibilizados }\end{array}$ & Artigos selecionados \\
\hline $\begin{array}{l}\text { Profissionais da educação e } \\
\text { precarização; precarização do } \\
\text { trabalho docente }\end{array}$ & 20 & 06 \\
\hline
\end{tabular}

Após a leitura dos resumos dos vinte artigos, foram selecionados seis, com base no resumo, devido a aproximação com o objetivo deste estudo. Nos Quadros 2 e 3, a seguir, esses artigos estão relacionados pela classificação: autor (es)/artigo; revista/local e ano de publicação. 
Quadro 02. Artigos selecionados - Descritor "Gestão democrática na escola".

\begin{tabular}{|c|c|c|c|}
\hline №. & Autor (es) / Artigo & Revista / Local & $\begin{array}{c}\text { Ano } \\
\text { Publicação }\end{array}$ \\
\hline 01 & $\begin{array}{l}\text { OLIVEIRA, Dalila Andrade. La cuestión } \\
\text { docente: Brasil, las condiciones laborales } \\
\text { de los profesores de educación básica. }\end{array}$ & $\begin{array}{c}\text { Fund. Laboratório de } \\
\text { Políticas Públicas/Buenos } \\
\text { Aires }\end{array}$ & 2008 \\
\hline 02 & $\begin{array}{l}\text { VIEITEZ, C. G.; DAL RI, N. M. Educação no } \\
\text { movimento social: a luta contra a } \\
\text { precarização do ensino público. In: LIMA, } \\
\text { F. C. S.; SOUZA, J. U. P.; CARDOZO, M. J. } \\
\text { P. B.. (Org.). Democratização e educação } \\
\text { pública. }\end{array}$ & $\begin{array}{l}\text { Sendas e veredas/ São } \\
\text { Luís }\end{array}$ & 2011 \\
\hline 03 & $\begin{array}{l}\text { CURY, C. R. J. A gestão democrática na } \\
\text { escola e o direito à educação. }\end{array}$ & $\begin{array}{l}\text { Revista Brasileira de } \\
\text { Política e Administração } \\
\text { da Educação, Goiânia } \\
\text { Educar em Revista / } \\
\text { Curitiba }\end{array}$ & 2007 \\
\hline
\end{tabular}

Quadro 03. Artigos selecionados - Descritor "Os profissionais da educação e a precarização do trabalho docente".

\begin{tabular}{|c|l|c|c|}
\hline No. & \multicolumn{1}{|c|}{ Autor (es) / Artigo } & Revista / Local & $\begin{array}{c}\text { Ano } \\
\text { Publicação }\end{array}$ \\
\hline 01 & $\begin{array}{l}\text { ESTEVE, J. M. O mal-estar docente: a sala } \\
\text { de aula e a saúde dos professores. }\end{array}$ & EDUSC/ Bauru, SP & 1999 \\
\hline 02 & $\begin{array}{l}\text { MIRANDA, Kênia. O trabalho docente na } \\
\text { acumulação flexível. Trabalho } \\
\text { apresentado no GT Trabalho e Educação, } \\
\text { 2006. }\end{array}$ & $\begin{array}{l}\text { Revista Brasileira de } \\
\text { Estudos Pedagógicos / } \\
\text { Brasília }\end{array}$ & 2015 \\
\hline 03 & $\begin{array}{l}\text { ENGUITA, M. F. A ambiguidade da } \\
\text { docência: entre o profissionalismo e a } \\
\text { proletarização. }\end{array}$ & Teoria \& Educação & 1999 \\
\hline
\end{tabular}

Os artigos foram lidos na íntegra para que fosse possível identificar: as ideias principais; a sistematização das ideias encontradas por meio de fichamentos e a categorização temática para proceder na análise dos dados. O conteúdo extraído e analisado a partir do material selecionado ofereceu o embasamento teórico para este trabalho, conforme se apresenta nos tópicos a seguir.

\section{DIVISÃO DO TRABALHO NA MODERNA SOCIEDADE CAPITALISTA}

A divisão do trabalho retrata a sociedade dividida em classes sociais: a classe dos proprietários dos meios de produção e a classe explorada (proletária).

As modificações ocorridas no processo de trabalho em decorrência da reestruturação produtiva, a partir da década de 1970, têm atingido com muita intensidade todos os trabalhadores, entre eles, os profissionais da educação e os professores. Para Karl Marx o trabalho na sociedade capitalista é movimento de criação de mercadorias, onde a força de trabalho é também mercadoria. Assim, o comprador da força de trabalho consome-a, fazendo o vendedor dela trabalhar. O trabalhador, ao despender suas energias psicofísicas no trabalho, submete-se a exploração capitalista e constitui-se e valor de troca fundamental no processo de produção capitalista. 
Muitos dos elementos propostos por Taylor estão bem presentes nas propostas atuais de gestão de mercado para o público, apesar de o discurso ser de modernização e democratização na gestão.

A luta pela democratização da sociedade também fez parte do processo de democratização da educação. Desta forma, a gestão democrática é um fim, e não apenas um meio, já que não é simplesmente uma mudança na concepção de gestão, que passaria da tecnocrática, vinculada aos preceitos do Fordismo e Toyotismo, para a gestão democrática. Para Cury (2007, p. 12) a concepção de gestão democrática é representada como sendo:

A gestão democrática da educação é, ao mesmo tempo, por injunção da nossa Constituição (art. 37) (Brasil, 1988): transparência e impessoalidade, autonomia e participação, liderança e trabalho coletivo, representatividade e competência. Voltada para um processo de decisão baseado na participação e na deliberação pública, a gestão democrática expressa um anseio de crescimento dos indivíduos como cidadãos e do crescimento da sociedade enquanto sociedade democrática.

\section{OS PROFISSIONAIS DA EDUCAÇÃO}

Assim como os demais trabalhadores que vêm sofrendo transformações nas condições de trabalho, os profissionais da educação não estão alheios a este processo de mudança. Desse modo, cabe compreender as particularidades dessa categoria em sua articulação com a totalidade social e compreender sua participação no processo de construção da gestão democrática.

Segundo Saviani (1984), a análise feita por Marx não pode ser aplicada de forma plena ao trabalho na escola em virtude da natureza do fenômeno do processo educativo. A escola, em razão da natureza do seu trabalho pedagógico, do seu "produto" subjetivo e da matéria-prima com que trabalha, apresenta muita especificidade. Não é objetivo desta discussão adentrar tal polêmica existente na analogia entre fábrica e escola, mas sim contribuir na discussão do problema assemelha a condição de trabalho docente à precarização dos demais trabalhadores. Isso ocorre porque os trabalhadores assalariados em geral estão sujeitos à alienação, no sentido de não ter domínio sobre o processo de trabalho e seu produto, e a exploração por meio da extração de mais valia, uma vez que nem toda a jornada de trabalho despendida com o fazer pedagógico é paga, ao contrário, as atividades docentes tendem a estenderem-se para além do horário e local de trabalho.

Segundo Enguita (1991) os professores no Brasil sofrem um processo de proletarização acelerado, apresentam algumas características que podem situá-los, mesmo levando-se em conta a situação ambivalente que vivem, mais um campo de constituição como classe trabalhadora do que como uma categoria de profissionais liberais. Destaca, ainda, que as condições de trabalho têm imposto uma situação extremamente precária que os distancia, em termos de renda e prestígio, do profissionalismo; e as conquistas, quando ocorrem, se dão através de lutas sindicais, através de entidades que estão organizadas muito mais segundo os moldes dos sindicatos de trabalhadores do que de associações profissionais.

Desta forma, a organização do espaço e do sistema escolar nos dias atuais objetiva conformar e preparar a força de trabalho, mantendo os estudantes sempre ocupados, esta organização não foi fruto do desenvolvimento natural da sociedade. O papel que a escola cumpre atualmente na sociedade teve suas origens com o advento da Revolução Industrial. Em outras palavras, a escola estatal nasceu com o capitalismo ou sistema de produção capitalista. Assim, entende-se que a escola reflete a sociedade em que vivemos e o processo histórico no qual estamos inseridos, podendo relacionar escola pública e estatal como escola burguesa planejada pelos governos burgueses que estão no poder a partir do advento do capitalismo. 


\section{O PROCESSO DE PROLETARIZAÇÃO}

Enguita (1991) define proletarização como um processo desigual onde um grupo de trabalhadores perde o controle sobre seus meios de produção, o objetivo de seu trabalho e a organização de suas atividades. O autor afirma ainda que o docente perdeu ao longo do tempo seu poder de decisão para o resultado de seu trabalho, pois este já lhe chega pronto em forma de disciplinas, horários, programas, livros didáticos, normas de avaliação, etc.

O que vemos hoje são "métodos replicáveis" de apostilas ou venda de sistemas de ensino ou parcerias que vendem um pacote pronto. Tudo isso provoca a diminuição da autonomia do professor que recebe o material pronto para utilizar em cada dia na sala de aula e conta com um supervisor para verificar se está tudo certo. Há ainda, a lógica da premiação por desempenho, que estabelece valores, como o da competitividade entre alunos, professores e escolas. A esse respeito, Peroni (2012) questiona e contraria a ideia de que a premiação dos mais capazes e o estabelecimento de competição entre os pares induza à qualidade.

Sobre os impactos da meritocracia, recentemente, Hout \& Elliott (2011, p. 4.26) afirmaram que:

Os programas de incentivo baseados em testes, como concebidos e implementados nos programas que foram cuidadosamente estudados, não têm aumentado o desempenho dos estudantes o suficiente para que os Estados Unidos atinjam os níveis de realização mais altos de outros países. Quando avaliados usando testes de baixo impacto pertinentes, que são menos susceptíveis de serem inflados pelos próprios incentivos dados, os efeitos globais sobre o desempenho tendem a ser pequenos e são efetivamente zero para um certo número de programas.

Outro fator é a fragmentação da categoria docente, que começa pelas diferentes formas de contratos de trabalho em exercício numa mesma escola ou rede educacional, ou de um mesmo trabalhador em locais de trabalho diferentes, havendo, porém, ataques direcionados ao conjunto dos trabalhadores da educação como: a previdência que vem sendo colocada nas mãos da iniciativa privada; a substituição de planos de carreira por avaliações de desempenho e produtividade que destroem a paridade entre profissionais da ativa, também o faz aos aposentados e o total sucateamento das condições objetivas de trabalho.

A não participação dos professores faz com que o mesmo transforma-se apenas em um comunicador, seu trabalho sendo considerado meramente técnico, ou seja, qualquer pessoa pode, dentro da concepção neoliberal de educação, lecionar aulas uma vez que pode seguir o currículo que já vem pronto.

\section{ANÁLISE E DISCUSSÃO}

Entre as principais implicações para a precarização do trabalho docente está a diminuição da autonomia do professor, que não participa do projeto de gestão e tomada de decisão na escola e recebe material pronto para utilizar na sala de aula. Além disso, os instrumentos de controle são instaurados para averiguar o cumprimento do trabalho, como por exemplo, a existência de profissionais da educação que assumem a função de supervisionar o trabalho e a visão gerencial estratégica centrada nos gastos e na eficiência operacional. Com isso, a valorização da estrutura hierárquica dentro das instituições educacionais, o que reduz os docentes a mero executores do trabalho pedagógico e gestão, bem como sujeitam-se à intensificação da exploração.

\section{CONSIDERAÇÕES FINAIS}

Os resultados apontaram que o trabalho docente vem passando por mudanças estruturais que se impuseram sobre os profissionais da educação. As condições impostas têm 
ocasionado mudanças pretensiosamente negativas na categoria, impondo a estes profissionais, novas formas de lidar com o cotidiano escolar, com o seu trabalho e também com a resistência.

Nesse sentido, tais condições de trabalho, tem efeito negativo sobre a construção de uma gestão democrática para a melhoria do trabalho docente, pois a mesma pressupõe a participação de todos no projeto político-pedagógico, em conselhos, eleição para diretores e a autonomia financeira. São processos pedagógicos de aprendizagem da democracia para a comunidade escolar que pressupõe processos de trabalho em que docentes situem-se como sujeitos na construção do processo de trabalho, bem como ofereçam as condições materiais de trabalho necessárias para o exercício da participação e gestão democrática na escola.

\section{REFERÊNCIAS}

CURY, C. R. J. A gestão democrática na escola e o direito à educação. Revista Brasileira de Política e Administração da Educação, Goiânia, v.23, n.3, p. 483-495, set./dez.2007.

ENGUITA, M. F. A ambiguidade da docência: entre o profissionalismo e a proletarização. Teoria \& Educação, n. 4, 1991.

ENGUITA, M. F. A face oculta da escola: educação e trabalho no capitalismo. Porto Alegre: Artes Médicas, 1989.

ESTEVE, J. M. O mal-estar docente: a sala de aula e a saúde dos professores. Bauru, SP: EDUSC, 1999.

FERNANDES, M. J. S. O professor coordenador pedagógico nas escolas estaduais paulistas: da articulação pedagógica ao gerenciamento das reformas educacionais. Educação e Pesquisa, São Paulo, v. 38, n. 4, p. 799-814, out./dez. 2012. https://doi.org/10.1590/S1517-97022012000400002

FERNANDES, F. A revolução burguesa no Brasil: ensaio de interpretação sociológica. Rio de Janeiro: Zahar, 1981.

HOUT, m.; ELLIOTT, S. V. Incentives and test-based accountability in education. Washington,DC: National Academy of Sciences, 2011.

KRAWCZYK, N. Conhecimento crítico e política educacional: um diálogo difícil, mas necessário. In: KRAWCZYK, N. (Org.). Sociologia do ensino médio: crítica ao economicismo na política educacional. São Paulo: Cortez, 2014.

MIRANDA, Kênia. O trabalho docente na acumulação flexível. Trabalho apresentado no GT Trabalho e Educação, 2006.

OLIVEIRA, Dalila Andrade. La cuestión docente: Brasil, las condiciones laborales de los profesores de educación básica. 1aㅡ ed. Buenos Aires: Fund. Laboratório de Políticas Públicas, 2008.

PERONI, V. M. V. A gestão democrática da educação em tempos de parceria entre o público e o privado. Pro-Posições, Campinas, v. 23, n. 2 (68), p. 19-31, maio/ago. 2012.

POULANTZAS, N. 1978a. State, Power, Socialism. London : New Left. 
SANFELICE, J. L. A política educacional do estado de São Paulo: apontamentos. Nuances: estudos sobre educação, Presidente Prudente, n. XVII, v. 17, n. 18, p. 146-159, jan./dez. 2010.

SAVIANI, Dermeval. Escola e Democracia. 3. ed. São Paulo: Cortez, 1984.

VIEITEZ, C. G.; DAL RI, N. M. Educação no movimento social: a luta contra a precarização do ensino público. In: LIMA, F. C. S.; SOUZA, J. U. P.; CARDOZO, M. J. P. B.. (Org.).

Democratização e educação pública: sendas e veredas. São Luís: Edufma, 2011. v. 1, p. 133-165. 